BJHS 51(2): 261-280, June 2018. C British Society for the History of Science 2018. This is an Open Access article, distributed under the terms of the Creative Commons Attribution licence (http://creativecommons.org/licenses/by/4.0/), which permits unrestricted re-use, distribution, and reproduction in any medium, provided the original work is properly cited.

doi:10.1017/S0007087418000055 First published online 26 March 2018

\title{
Science and self-assessment: phrenological charts 1840-1940
}

\author{
FENNEKE SYSLING*
}

\begin{abstract}
This paper looks at phrenological charts as mediators of (pseudo-)scientific knowledge to individual clients who used them as a means of self-assessment. Phrenologists propagated the idea that the human mind could be categorized into different mental faculties, with each particular faculty represented in a different area of the brain and by bumps on the head. In the US and the UK popular phrenologists examined individual clients for a fee. Drawing on a collection of phrenological charts completed for individual clients, this paper shows how charts aspired to convey new ideals of selfhood by using the authority of science in tailor-made certificates, and by teaching clients some of the basic practices of that science. Hitherto historians studying phrenology have focused mainly on the attraction of the content of phrenological knowledge for the wider public, but in this paper I show how the charts enabled clients to participate actively in creating knowledge of their own bodies and selves.
\end{abstract}

\section{Introduction}

This paper examines how individual consumers in the nineteenth century were encouraged to use (pseudo-)science as a means of self-assessment. The central empirical focus is on phrenological charts: individual records of information in the form of a certificate or booklet that clients received after a visit to the phrenologist that included a list or table with the results of the phrenological examination.

Phrenologists claimed that the human mind consisted of different mental faculties or organs, with each particular faculty represented in a different area of the brain. On the head the development of these areas could be studied by analysing the bumps, which developed where areas of the brain were particularly active. Thus the bumps and indentations were manifestations of the interior self. Around the year 1800 phrenology was a subject of serious scientific debate, but when it became known to a wider public in the UK in the late 1810 s the new science became increasingly labelled quackery by the scientific elites and relegated to the margins of scientific communities. ${ }^{1}$ Nevertheless it

\footnotetext{
* Department of History and Art History, University of Utrecht, Drift 6, 3512 BS, Utrecht, the Netherlands. Email: f.h.sysling@uu.nl.

I would like to thank Charlotte Sleigh, the two anonymous referees and colleagues at the History of Science Society Annual Meeting and at the Cultural History Seminar at the University of Utrecht where I presented earlier versions of this paper. Special thanks are owed to Teresa Johnson and Russell Johnson of the UCLA Library Special Collections for Medicine and the Sciences. Research for this article was supported by the Netherlands Organisation for Scientific Research (275-69-008).

1 See, for the history of phrenology, Roger Cooter, The Cultural Meaning of Popular Science: Phrenology and the Organization of Consent in Nineteenth-Century Britain, Cambridge: Cambridge University Press,
} 
remained popular far into the twentieth century, especially in the US and the UK, where generations of popular phrenologists monetized their knowledge with the sale of phrenology handbooks, manuals and journals, and with sessions in which they analysed clients by observation, measurement and a manual examination of their heads.

After these sessions, clients sometimes received a written delineation of their character, but more often a standardized chart was completed for them. This paper is based on more than 160 completed phrenological charts, about a hundred of which are from the UCLA Library Special Collections for Medicine and the Sciences. ${ }^{2}$ They date from the 1840-1940 period and come in various designs, sizes and colours. Some phrenologists used broadsheet certificates with official-looking decoration; others published popular booklets on phrenology, including explanations of how the brain works and a simple table for the client to complete. 'There have been many charts designed for the registering of character', said a chart by the phrenologist couple $\mathrm{Mr}$ and $\mathrm{Mrs}$ Stackpool O'Dell from London in the early twentieth century, and 'there will probably be many more'. Theirs, it said, was just as good as the others. ${ }^{3}$ Some charts included advice on suitable occupations, marriage partners and - less often - health measures. What they have in common is a list or table of the phrenological faculties, blanks to fill in how people scored and, except for the simplest charts, text on how the results should be read. The list of phrenological faculties remained remarkably consistent over the course of a hundred years.

This paper brings a focus on material and practice to the historiography of phrenology. Most studies of phrenology until now have focused mainly on intellectual discussions between phrenologists and anti-phrenologists and on the attraction of the ideas of (semi-)professional phrenologists for the wider public. Phrenology has traditionally been defined by historians such as Steven Shapin and Roger Cooter as a reform science that was employed by the rising middle classes to call for educational and criminal reforms and at the same time to stake out a position for themselves in society. ${ }^{4}$ More recently, John van Wyhe has argued that although some people used the tenets of phrenology to call for social reform, many others did not, or used phrenology for more conservative causes. 'The possessor' of phrenological knowledge, writes Van Wyhe, 'could use it as an

1984; Madeleine B. Stern, Heads and Headlines: The Phrenological Fowlers, Norman: University of Oklahoma Press, 1971; David De Giustino, Conquest of Mind: Phrenology and Victorian Social Thought, London: Croon Helm, 1975; Sherrie Lynne Lyons, Species, Serpents, Spirits and Skulls: Science and the Margins in the Victorian Age, Albany: SUNY Press, 2009; John van Wyhe, Phrenology and the Origins of Victorian Scientific Naturalism: Science, Technology and Culture, 1700-1945, Aldershot: Ashgate, 2004; and many others.

2 Others are from the Wellcome Library in London, the US National Library of Medicine and other collections, and many are digitized and available online at archive.org.

3 A Phrenological Chart of Character (with Supplementary Tables) by Stackpool E. O’Dell \& Mrs. Stackpool E. O'Dell, London: The London Phrenological Institution, n.d., History \& Special Collections for Medicine and the Sciences, University of California, Los Angeles (UCLA) Library Special Collections, WB 365 O23p 1931. Completed for Mr Davis, 18 February 1935.

4 Cooter, op. cit. (1); and Steven Shapin, 'Phrenological knowledge and the social structure of early nineteenth-century Edinburgh', Annals of Science (1975) 32(3), pp. 219-243. For a recent example of the intellectual history of phrenology see Bill Jenkins, 'Phrenology, heredity and progress in George Combe's Constitution of Man', BJHS (2015) 48, pp. 455-473. 


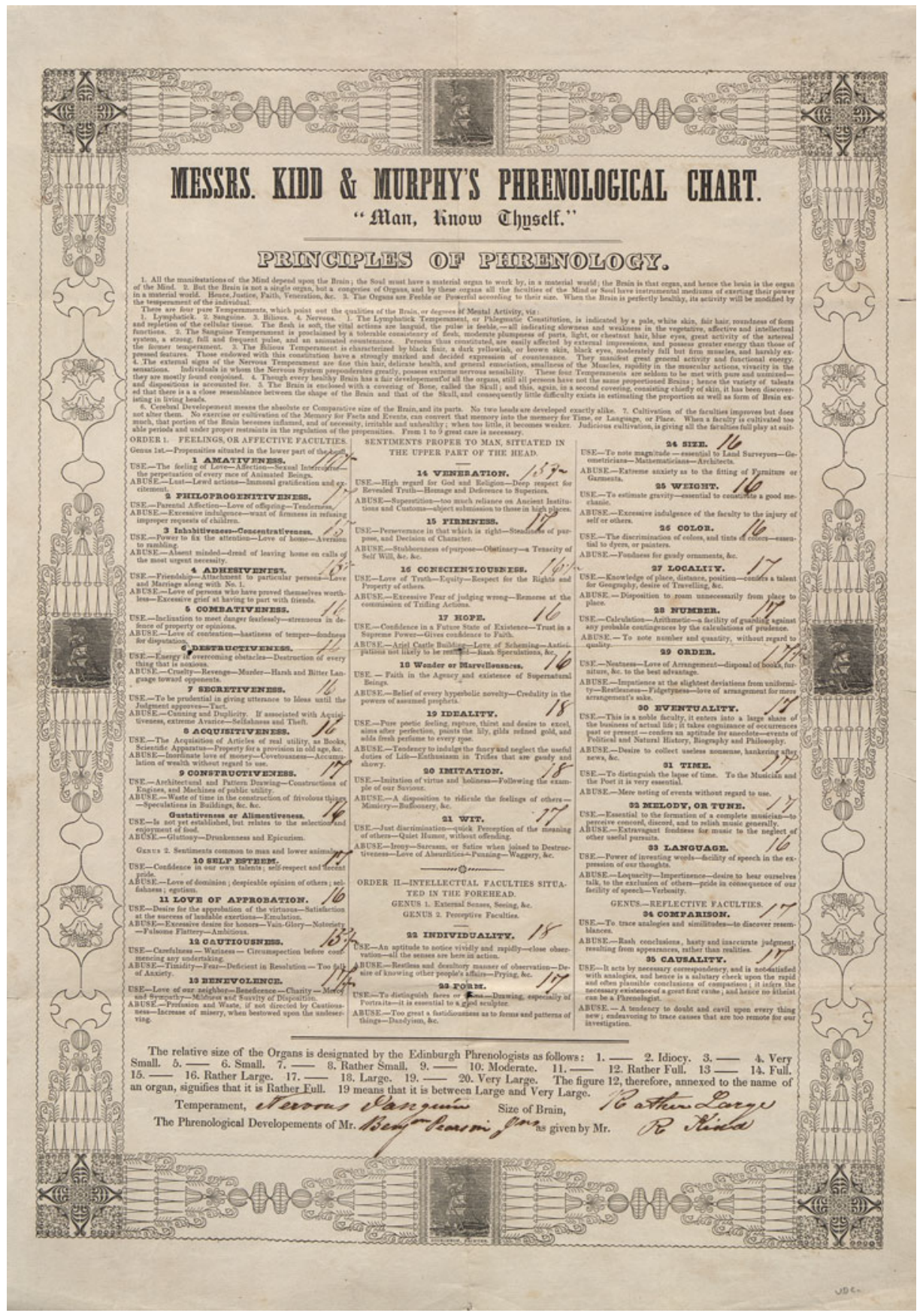

Figure 1. Messrs. Kidd \& Murphy's Phrenological Chart, c.1850, History \& Special Collections for Medicine and the Sciences, UCLA Library Special Collections. 
argumentative weight to throw onto the side of whatever endeavours they pursued', and we should therefore define phrenology as a science of 'personal authority'. 5

Not only was phrenology attractive because it gave those who knew about it authority to speak about others and the world, but also the role of phrenology in the making of the 'self' - the idea of an internalized inner self that can be understood and shaped - has been recognized by historians. According to Jan Goldstein, for example, who writes about France, phrenology furnished 'the conceptual basis and the language for a distinctive experience of interiority'. ${ }^{6}$ With the concepts of phrenology, individual people were able to see themselves as having an individual self, located in the brain and reflected in the shape of the head, a self that was also knowable and malleable. In an encounter with the (supposedly) scientific discourse of phrenology, people learnt facts and theories and incorporated them in their lives. As Van Wyhe mentions, 'The authority and certitude that scientific "facts" had acquired in the early nineteenth century were becoming more and more familiar to lay audiences'. ${ }^{7}$ These new ideas could persuade people to think about themselves in different terms.

Notions of the self, historians, philosophers and sociologists have shown, came about in an interplay between the larger intellectual forces of science (and the state) on the one hand, and the micromanagement of the self and identity on the other. ${ }^{8}$ Following those historians of science and self who have proposed an emphasis on self-making through practice and performance, this paper focuses on micro-management rather than on the ways in which phrenological publications provided new intellectual options for selfhood. ${ }^{9}$ Individual practices of the self can take many forms, from diary writing to confessing, from reading a self-help manual to talking about one's emotions. This paper looks at the use of phrenological charts to show how they were a new mode of self-reflection that relied on the practice of scientific techniques. Reading and listening to talks about phrenology did teach people about the head, the brain and the mind, but less

5 John van Wyhe, 'Was phrenology a reform science? Towards a new generalization for phrenology', History of Science (2004) 42, pp. 313-331, 325.

6 Jan Goldstein, The Post-revolutionary Self: Politics and Psyche in France, 1750-1850, Cambridge, MA: Harvard University Press, 2005, pp. 310.

7 Van Wyhe, op. cit. (5), p. 318.

8 Nikolas Rose, Governing the Soul: The Shaping of the Private Self, London: Free Association Books, 1989; Rose, Inventing Ourselves: Psychology, Power, and Personhood, Cambridge: Cambridge University Press, 1996, pp. 22-40; Michel Foucault, 'Technologies of the self', in Luther H. Martin, Huck Gutman and Patrick H. Hutton (eds.), Technologies of the Self: A Seminar with Michel Foucault, Amherst: University of Massachusetts Press, 1988, pp. 16-49; Charles Taylor, Sources of the Self: The Making of Modern Identity, Cambridge, MA: Harvard University Press, 1989; Anthony Giddens, Modernity and Self-Identity: Self and Society in the Late Modern Age, Stanford, CA: Stanford University Press, 1991. For a recent call to study the historical self see Lynn Hunt, 'The self and its history', American Historical Review (2014) 119(5), pp. 1576-1586.

9 Elwin Hofman, 'How to do the history of the self', History of the Human Sciences (2016) 29, pp. 8-24; and Nima Bassiri, 'What kind of history is the history of the self? New perspectives from the history of mind and brain medicine', Modern Intellectual History (2017) advance online publication, pp. 1-13. For micromanagement see, for example, Arianne Baggerman and Rudolf Dekker (eds.), Controlling Time and Shaping the Self: Developments in Autobiographical Writing since the Sixteenth Century, Leiden: Brill, 2011; and Molly McCarthy, The Accidental Diarist: A History of the Daily Planner in America, Chicago: The University of Chicago Press, 2013. 
directly about their own individuality. With a visit to the phrenologist and the purchase of a chart, clients were provided with a piece of science that was tailored to themselves, and that encouraged them to do phrenology and to reflect on its findings. The charts were therefore effective mediators between science and individual self-making. ${ }^{10}$

This also provides an alternative viewpoint on the popularization of science. Breaking down the distinction between professional and popular science, historians have shown how consumers of science were not passive receivers of simplified scientific knowledge. While studies of popular science in the nineteenth century have paid most attention to the popularizing of phrenology and other sciences through lectures, popular publications, museums and fairs, this paper follows historians such as Anne Secord and Melanie Keene who have started to look at tactile and interactive public experiences with science, and at the public house and the home as places where lower and middle classes did science. ${ }^{11}$ This approach emphasizes how individuals became experts and produced their own knowledge, in this case new understandings of the body and the inner self.

In what follows, this paper shows how individual consumers of phrenology learnt not only the outcome of the phrenological examination, but also how to read a table, how to interpret the numbers and how to apply the phrenological techniques of observation and measurement to themselves (or to friends and family). They were to take up the measuring rod and to start touching their own head to understand what lay beneath the bumps. The next section first introduces the phrenological charts, their creators and the clients who bought them. The paper then explains how these charts created authority with their scientific layout and use of numbers, and how consumers of the charts were taught how to understand these. The final section details how the charts stimulated an engagement with scientific techniques. I conclude that phrenological charts stimulated people effectively to engage with scientific techniques, with their message that self-

10 Both reading about the concepts of phrenology and the embodied practice of science would fit within Michel Foucault's definition of technologies of the self. Technologies of the self, he says, 'permit individuals to effect by their own means or with the help of others a certain number of operations on their own bodies and souls, thought, conduct, and way of being, so as to transform themselves in order to attain a certain state of happiness, purity, wisdom, perfection, or immortality'. Martin, Gutman and Hutton, op. cit. (8), p. 18.

11 Anne Secord, 'Science in the pub: artisan botanists in early nineteenth-century Lancashire', History of Science (1994) 32(3), pp. 269-315; and Melanie Keene, 'Familiar science in nineteenth-century Britain', History of Science (2014) 52(1), pp. 53-71. See also John van Wyhe, 'The diffusion of phrenology through public lecturing', in Aileen Fyfe and Bernard Lightman (eds.), Science and the Marketplace: NineteenthCentury Sites and Experiences, Chicago: The University of Chicago Press, 2007, pp. 60-96; Joe Kember, John Plunkett and Jill Sullivan (eds.), Popular Exhibitions, Science and Showmanship, 1840-1910, London: Pickering \& Chatto, 2012; Roger Cooter and Stephen Pumfrey, 'Separate spheres and public places: reflections on the history of science popularization and science in popular culture', History of Science (1994) 32, pp. 237-267, James A. Secord, 'Knowledge in transit', Isis (2004) 95, pp. 654-672, Bernard Lightman, Victorian Popularizers of Science: Designing Nature for New Audiences, Chicago: The University of Chicago Press, 2007; Jonathan R. Topham, 'Rethinking the history of science popularization/popular science', in Faidra Papanelopoulou, Agustí Nieto-Galan and Enrique Perdiguero (eds.), Popularizing Science and Technology in the European Periphery, 1800-2000, Aldershot: Ashgate, 2009, pp. 1-20; Katherine Pandora, 'Knowledge held in common: tales of Luther Burbank and science in the American vernacular', Isis (2001) 92, pp. 484-516; and Katherine Pandora and Karen A. Rader, 'Science in the everyday world: why perspectives from the history of science matter', Isis (2008) 99, pp. 350-364. 
assessment was a skill that needed to be learnt. Charts had the ambition to produce autonomous, active and science-minded people who took responsibility for their own actions and future. That does not mean that phrenological ideas and practices were the only or the most important means of self-making in this period but it does show the entanglement of scientific practices with the making of autonomous selves.

\section{Phrenologists, clients and charts}

Developed by German physician Franz Joseph Gall in 1796, phrenology became popular in the early nineteenth century. The movement is usually described as having a scientific phase and then a popular phase, and although these two are not so easily separated, phrenology was popular long after professional scientists had ceased to take it seriously. It was not thanks to Gall that phrenology came to be seen as a science for all. John van Wyhe notes that during Gall's lecture tour of Europe he 'repeatedly told his audiences that his system was too difficult for them to try'. ${ }^{12}$ Gall's successors, however, managed to spread phrenology among a wider audience: Johann Spurzheim and George Combe repackaged the new science and made it more appealing in Great Britain, whence it spread back to the Continent and to the United States. ${ }^{13}$

In the US all sorts of popular science thrived during the antebellum era. When the professionalization of science began, according to Katherine Pandora, professional scientists 'had to contend with the fact that successive cohorts of Americans had already experienced the manifestations of popular science as normative'. ${ }^{14}$ Phrenology had spread most widely in the US between the 1830s and the 1850s but its popularity lasted until the end of the nineteenth century. In Britain phrenology had a popular phase in the 1830s and 1840s, and again in the 1860s and 1870s, and there too the middle-class public was acquainted with science through popular publications, lectures and other ways in which science was made, in Melanie Keene's words, 'familiar science'. ${ }^{15}$ The century-long enthusiasm for phrenology on both sides of the Atlantic is reflected in the collection of charts used for this article, which date from c.1840 to 1940. The 1880s and 1890s are best represented and in the twentieth century the numbers drop. Although there are two early British charts from the 1840s, those from Great Britain date mostly from after 1880 .

Two of the best-known promoters of phrenology in the United States from the 1840s onwards were the brothers Orson and Lorenzo Fowler, their partner Samuel Wells and Lorenzo's wife Lydia. They set up a phrenology practice that also included a publishing firm and museum, the Phrenological Cabinet, in Manhattan in 1836, an organization which survived into the beginning of the twentieth century. In the early 1860 s Lorenzo Fowler and his family migrated to Britain, where they founded the Fowler

12 Van Wyhe, op. cit. (5).

13 For England see Van Wyhe, op. cit. (11).

14 Katherine Pandora, 'Popular science in national and transnational perspective: suggestions from the American context', Isis (2009) 100, pp. 346-358, 351; and Carla Bittel, 'Woman, know thyself: producing and using phrenological knowledge in 19th-century America', Centaurus (2013) 55, pp. 104-130.

15 Keene, op. cit. (11). 
Institute. From here Lorenzo gave courses in practical phrenology, thus creating for the family a transatlantic influence. ${ }^{16}$ The Fowlers and Samuel Wells together produced about one-third of the charts used for this article, including those that they published and that were subsequently used by other phrenologists. Their Illustrated SelfInstructor was first published in 1849 and went through more than twenty editions.

Another family whose charts are well represented in the archives was the Stackpool O'Dell family mentioned earlier. They (re-)established a London Phrenological Institution in the late nineteenth century, and Mrs Stackpool O'Dell continued the phrenological business into the late 1930s. Finally, there are many other charts from lesser known and often itinerant phrenologists, who have left few other traces in the archives. Roger Cooter's bio-bibliography of the British Isles includes listings for hundreds of practical, popular phrenologists. According to Cooter, there were still over 150 practical 'professors' of phrenology after 1860, most from humble backgrounds, who practised their trade on the piers of Blackpool and Brighton. In the US there were thousands of travelling phrenologists throughout the nineteenth century. ${ }^{17}$

Thus whether in the Phrenological Cabinet in New York, or through an examination or show in a small-town hotel room by a travelling phrenologist, or on the pier at Brighton, thousands of white Americans and Britons encountered phrenology in some form or other. The lure of phrenology, in the words of Sherrie Lynn Lyons, was that 'humans could be investigated according to the tenets of science' and would acquire knowledge about themselves that was new and truer than what they already knew. ${ }^{18}$ As one booklet by the American practical phrenologist Charles Olin said, 'By its aid we are able to gauge our own capacity, to know our strong and weak points, and to learn what vices most easily beset us' ${ }^{19}$ Of course, visits to phrenologists also had an aspect of entertainment to them and some visitors likely took the charts more seriously than others.

One of phrenology's more famous clients was Alfred Russel Wallace, who took phrenology very seriously and went to a phrenologist (at least) three times in his life. In 1897 he was examined by James Webb, and earlier by James Q. Rumball and Edwin T. Hicks. After Webb's visit Wallace commented in a letter, 'He [Webb] says (and I believe him) let him examine a man's head and he knows him better than his most intimate friends know him - better, often, than he knows himself'. ${ }^{20}$ Years later, he was still convinced that phrenologists possessed true knowledge, as he wrote in his 1905 biography:

16 Stern, op. cit. (1).

17 Cooter, op. cit. (1), p. 260; and Erika Janik, Marketplace of the Marvelous: The Strange Origin of Modern Medicine, Boston, MA: Beacon Press, 2014, p. 68. Janik says there were more than twenty thousand travelling phrenologists in the US, but it is unclear how she arrived at that number.

18 Lyons, op. cit. (1), p. 83. See also van Wyhe, op. cit. (5).

19 Charles H. Olin, Phrenology: How to Tell Your Own and Your Friend's Character from the Shape of the Head, Philadelphia: The Penn Publishing company, 1910, p. 19, UCLA Library Special Collections BF 871. O46p 1910.

20 Letter from Alfred Russel Wallace, Corfe View, Parkstone, Dorset, to William Greenell Wallace, 31 October 1897, Natural History Museum London, Wallace Letters Online, WCP1251.1030. 
during my early residence at Neath after my brother's death, I heard two lectures on the subject, and in both cases I had my character delineated with such accuracy as to render it certain that the positions of all the mental organs had been very precisely determined. It must be understood that the lecturers were both strangers, and that they each gave only a single lecture on their way to more important centres. In each case I received a large printed sheet, with the organs and their functions stated, and a number placed opposite to each to indicate its comparative size. ${ }^{21}$

All three charts that were completed for him survive. On Rumball's charts Wallace scores consistently high on all faculties. Webb gives him his highest score on firmness and comparison, Hicks on locality, an organ that determined 'the power of remembering places' and the 'desire to travel'. ${ }^{22}$

Phrenological charts were one of the many products of phrenology's propaganda machinery, along with journals, busts, posters and pamphlets. As Goldstein writes about France, 'Phrenology excelled in the production of "immutable mobiles," those enduring yet portable inscriptions that, according to Bruno Latour, both readily convey knowledge and persuade audiences of its scientific worth'. ${ }^{23}$ The charts were one of phrenology's paper tools; like books and journals, the charts helped to make the new knowledge authoritative while also tailoring it to the individual. ${ }^{24}$

Charts were standardized and cost less time to produce than written character delineations, and therefore they were also less expensive. One American advertisement mentioned the fees: 'For a mere verbal description with measurements .50 [dollar]; For measurements and full written descriptions 1.00; For measurements, full written descriptions and destiny 1.50'.25 In several cases, it was emphasized that the charts were 'intended to answer every purpose of a labored written description of character' ${ }^{26}$

21 Alfred Russel Wallace, My Life: A Record of Events and Opinions, vol., London: Chapman and Hall, 1905 , p. 257.

22 James Q. Rumball, Phrenological Development, completed for Alfred Russel Wallace, 14 October [1845], Bristol: Philip Rose, Natural History Museum London, Wallace Letters Online, WCP6102.7058; Phrenological Delineation of the Character of [Dr Wallace] by Mr. Edwin Thomas Hicks [n.p., c.1847], Natural History Museum, Wallace Letters Online WCP6101.7057; and Chart and Character of [A.R. Wallace], [n.p., 1897], Natural History Museum, Wallace Letters Online, WCP6110.7066.

23 Goldstein, op. cit. (6), pp. 290-291.

24 'Paper tools' was coined by Ursula Klein in Ursula Klein, Experiments, Models, Paper Tools: Cultures of Organic Chemistry in the Nineteenth Century, Stanford, CA: Stanford University Press, 2003, and used for formulas and other visual aspects of paper. 'Paper technology' is used as a wider term for aspects of paper: Volker Hess and J. Andrew Mendelsohn, 'Paper Technology und Wissensgeschichte', NTM Zeitschrift für Geschichte der Wissenschaften, Technik und Medizin (2013) 21(1), pp. 1-10; Hess and Mendelsohn, 'Case and series: medical knowledge and paper technology: 1600-1900', History of Science (2010) 48, pp. 287231; Anke te Heesen, 'The notebook: a paper-technology', in Bruno Latour and Peter Weibel (eds.), Making Things Public: Atmospheres of Democracy, Cambridge, MA: MIT Press, 2005, pp. 582-589. For filing see, for example, Rebecca Lemov, 'Filing the total human: anthropological archives from 1928 to 1963', in Charles Camic, Neil Gross and Michèle Lamont (eds.), Social Knowledge in the Making, Chicago and London: The University of Chicago Press, 2011, pp. 119-150.

25 Interesting to All: Professor Sturoc, from the College of Edinburgh, n.p., n.d., UCLA Library Special Collections, Ms Coll. no 504.063. For more examples see Cooter, op. cit. (1), p. 353.

26 C. Townsend, Improved Phreno-chart: Containing a Survey of the Constitution, and an Estimate of the Various Powers of Mind, and Traits of the Character, of [W.O. Wyckoff] as given [21 January 1860] by C. Townsend, Examiner, n.p., James \& Hopkins, 1859, UCLA Library Special Collections BF870.T747i 1859 , no page number, original emphasis. 
Phrenologist Ralph Brown wrote, 'A chart is as perfect as a carefully written personal description. But a carefully written analysis would bring out nice points of difference'. ${ }^{27}$ Charts can thus be seen as an abbreviated and abstract version of a verbal or written description of character that could conceivably be more complete and nuanced.

Together with the detailed and numbered assessment of themselves that they received, clients were also instructed in how to alter their behaviour. These instructions, based on the client's score, provided the client with suggestions directed towards a personality and lifestyle that phrenologists propagated: a life of moderation and self-control that also celebrated the home, work and health and emphasized the possibility of self-improvement. Most charts simply tell clients which faculties they should restrain and which they should cultivate. According to one Professor Hertig, 'The proper way to round out and balance the character is to choose circumstances and adopt habits that STIMULATE weak organs and REPRESS those of excessive influence'. ${ }^{28}$ The more elaborate charts made suggestions on what sort of behaviour would help to restrain or cultivate bad traits. The advice ranged from the commonsensical to the hilarious (to today's reader). William and Lilla Windsor's chart included, in its last pages, 'rules for cultivating deficient organs of the brain'. Organs, according to them, could be trained like muscles, mainly by imitating persons who score well on that trait. To cultivate vitativeness, for example, 'Observe aged persons and admire them; consider why they lived longer than others and imitate their virtues'. For sublimity, 'Enjoy sublime scenery ... comprehend the greatness of great objects'. ${ }^{29}$

Phrenology was therefore not so deterministic as one might expect for a system based on the innate shape of the skull. Phrenologists advocated an ideal that everyone could play an active role in their destiny and that phrenology would lead to deeper and genuine self-knowledge that could be used for self-improvement. ${ }^{30}$ This meant that the organs were malleable and that a person who stimulated his or her faculties would, necessarily, also change the size of the bump on the head. Few phrenologists elaborated on that, but according to one of them, Stephen Tracht, the time required to develop an organ was three weeks for two degrees in a child. 'In a young man, 18 yrs old, it takes three years to develop an organ. At the age of 25 , it takes five years. It is more difficult when you are 45 or 50 . But knowing one's fault is still better than not

27 Ralph Brown, A Delineation of the Character, Talents, Physiological Developments and Natural Adaptations of $\mathrm{Mr}$ [blank line], Melbourne: Mason, Firth \& M'Cutcheon, 1884, UCLA Library Special Collections, BF871.B879d 1884, p. 2.

28 [?] Hertig, A Phreno-organic Chart: For Recording Constitutional Conditions and Forces, Mental Developments and Characteristics by Prof. Hertig, Lecturer on Phrenology, Physiology, Physiognomy, Sexual Science, Love, Courtship, Matrimony, etc., n.p., 1902, UCLA Library Special Collections, BF871. H574p 1902.

29 William and Lilla Windsor, Phrenological Chart and Written Delineation of Character, published by the author, 1889, completed for S.L. Neblett, given at Waco, Texas, 8 November 1890, UCLA Library Special Collections, no inv. no, no page numbers.

30 See, for example, Orson Fowler, Self-Culture, and Perfection of Character: Including the Management of Youth, New York: Fowler's and Wells', 1853, p. iv. 
knowing. ${ }^{31}$ This shows how self-knowledge and self-improvement came to be seen as two sides of the same coin and how phrenology provided middle-class Americans and Britons with an early kind of self-help guidance. ${ }^{32}$ Of course phrenological discourse was often quite deterministic when phrenologists wrote in more general terms about women, Native Americans or African Americans. ${ }^{33}$

\section{Creating authority}

All the charts used for this paper include systematic arrangements of data, in the form of lists or tables and numbers. They have a 'spatial logic': the tables and lists 'draw things together, abstracting them' ${ }^{34}$ They made phrenological knowledge and its categories into something that looked systematic and stable but that was also easy to understand, comparable and persuasive. ${ }^{35}$ This is what phrenologist R. Dilks conveyed when he promoted his chart by emphasizing that it presented 'at one view, to the individual examined, his or her prominent and peculiar traits of character ... And also, to enable the examined to get at the practical benefits of Phrenology in the easiest, and shortest way'. ${ }^{36}$

According to their own accounts, Orson and Lorenzo Fowler started reading heads in 1833 or 1834, and their colleague Nelson Sizer related in his memoir that

[t]he public demanded some record of their estimate of the size of the organs in the heads they examined, and the chart was produced first as a slip, then a sheet, afterward a pamphlet, and later a book of two hundred pages, and thus practical Phrenology was begun and established. ${ }^{37}$

The evolution of charts Sizer described, however, is at odds with the fact that already in the 1830s, phrenological charts differed in size and layout. Two of Orson Fowler's earliest charts (of 1836 and 1838) are booklets of fifteen to twenty pages with lists of

31 Stephen Tracht, Stephen Tracht's Self-Instructor in Phrenology: With Descriptions of Organs; Illustrated; also Prepared for Practical Phrenologists, n.p., c.1907, UCLA Library Special Collections, BF871.T759s 1905, pp. 11-12.

32 See, for example, Lyons, op. cit. (1), pp. 51-86.

33 See, for example, Susan Branson, 'Phrenology and the science of race in antebellum America', Early American Studies: An Interdisciplinary Journal (2017) 15(1), pp. 164-193.

34 James Delbourgo and Staffan Müller-Wille, 'Introduction', Isis, special issue on 'listmania' (1012) 103, pp. 710-715.

35 Bruno Latour, 'Visualisation and cognition: drawing things together', in Henrika Kuklick (ed.), Knowledge and Society: Studies in the Sociology of Culture Past and Present, vol. 6, London: Jai Press, 1986, pp. 1-40; and Regula V. Burri and Joseph Dumit, 'Social studies of scientific imaging and visualisation', in Edward Hackett, Olga Amsterdamska, Michael E. Lynch and Judy Wajcman (eds.), The Handbook of Science and Technology Studies, Cambridge, MA: MIT Press, 2007, pp. 297-317, 297. See, for a recent example, Alondra Nelson, 'Bio science: genetic genealogy testing and the pursuit of African ancestry', Social Studies of Science (2008) 38(5), pp. 759-783.

36 Phrenological Chart: In Which Is Set Forth the Character and Talents of [Mr HC Smith] Given by Dr. R. Dilks, no publisher, completed 24 September 1853, UCLA Library Special Collections, Ms Coll. no 504.405 .

37 Orson Fowler, 'Practical phrenology defended', American Phrenological Journal and Miscellany (1841) 3, pp. 567-574, 567; and Nelson Sizer, Forty Years in Phrenology: Embracing Recollections of History, Anecdote, and Experience, New York: Fowler \& Wells, 1891, 15. 
the faculties and their description, in which the score was written in the margin. ${ }^{38}$ The numbered lists of faculties were copied from Gall, Spurzheim and Combe, and were adapted only slightly on the charts.

A chart of 1840 is the simplest version I have come across, a slip of paper with only the list of organs and the score. At the other extreme, large broadsheets were also published at this time. ${ }^{39}$ From the 1840 s onwards, lists with blanks for the scores become more popular (instead of scores in the margins). Interestingly, some of the earliest charts with this format are from the UK, suggesting that it was not the influential Fowlers only who were at the basis of chart design. ${ }^{40}$ Enos Stevens's chart, published in 1839, included the most elaborate table, with columns listing average scores ('general mediocrity'), under-average and over-average scores, for men and for women, and several columns with blanks for the score of the client. This table was apparently so difficult to read that it was never repeated. ${ }^{41}$ The table that the Fowlers started to use in their phrenology booklets from 1850 onward was the most widely published, and often used or copied by other phrenologists. It included a list of the organs and columns for the score, from 'small' on the right to 'very large' on the left (see Figure 2). Two extra columns, 'cultivate' and 'restrain', were checked if the client needed to work on a particular characteristic, and each square had a number that referred to a page in the same booklet where more information could be found.

Thanks to the layout of the charts, numbers were a central aspect. They suggest objectivity and measurability, although in practice the charts were not - with the exception of head circumference - filled with actual measurements but with a more subjective indication of size, which was then expressed quantitatively. In phrenology, the size of the head (usually measured by circumference) was the most straightforward thing to assess and much was made of it. Size of brain, phrenologists repeated, 'other conditions being

38 Orson Fowler, Phrenological Chart: Presenting a Synopsis of the Science of Phrenology, Baltimore: J. W. Woods, 1836, Library of Congress, Washington, DC, BF879.F78; and Fowler, Synopsis of Phrenology and the Phrenological Developments, Together with the Character and Talents of [Dr Asa Fitch] as Given by [John Salter], Philadelphia: Fowler and Brevoort, 1838, US National Library of Medicine, Bethesda, MD, 60230730R. Two other charts in which the scores are written in the margins are Synopsis of Phrenology and the Phrenological Developments: Together with the Character and Talents of [E.M. Dickinson] as Given by [N. Sizer] 11 Oct 1849, New York: Fowlers and Wells, 1849, UCLA Library Special Collections, BF870 F787s 1849; and Chart of the Phrenological Developments of [Charles S. Cowie[Collie?]] as Given by [Prof. W. Sied], New York: Wells \& Co., 1880, UCLA Library Special Collections BF871.C486 1880.

39 Clother Gifford, New Phrenological Chart by Clother Gifford and an Analysis of [Octavia A.Y. Norris], Character, Examined by [C.G. 7 September 1841], UCLA Library Special Collections, no inv. no; and Alfred Woodward, Developments of [Mr. Joseph Smith jr's] Head, 14 January 1840, Philadelphia. See www. josephsmithpapers.org/paperSummary/phrenology-chart-14-january-1840-b.

40 One of the earliest charts from the UK also includes a table: Phrenological Chart Taken by Mr. A.S. Hamilton, Practical Phrenologist, 19, West Strand, London: Cerebral Development of [Mr Bennett Junr], Canonbury, Islington: Grubbs, 1845, UCLA Library Special Collections, Ms Coll. no 504.081.

41 Enos Stevens, Rudiments of Mental Philosophy, and Phrenological Chart of [Redmond Conyngham], [Nov 5th 1842], Lampeter: Henry Miller Jr, UCLA Library Special Collections, BF870.S944r 1839. 

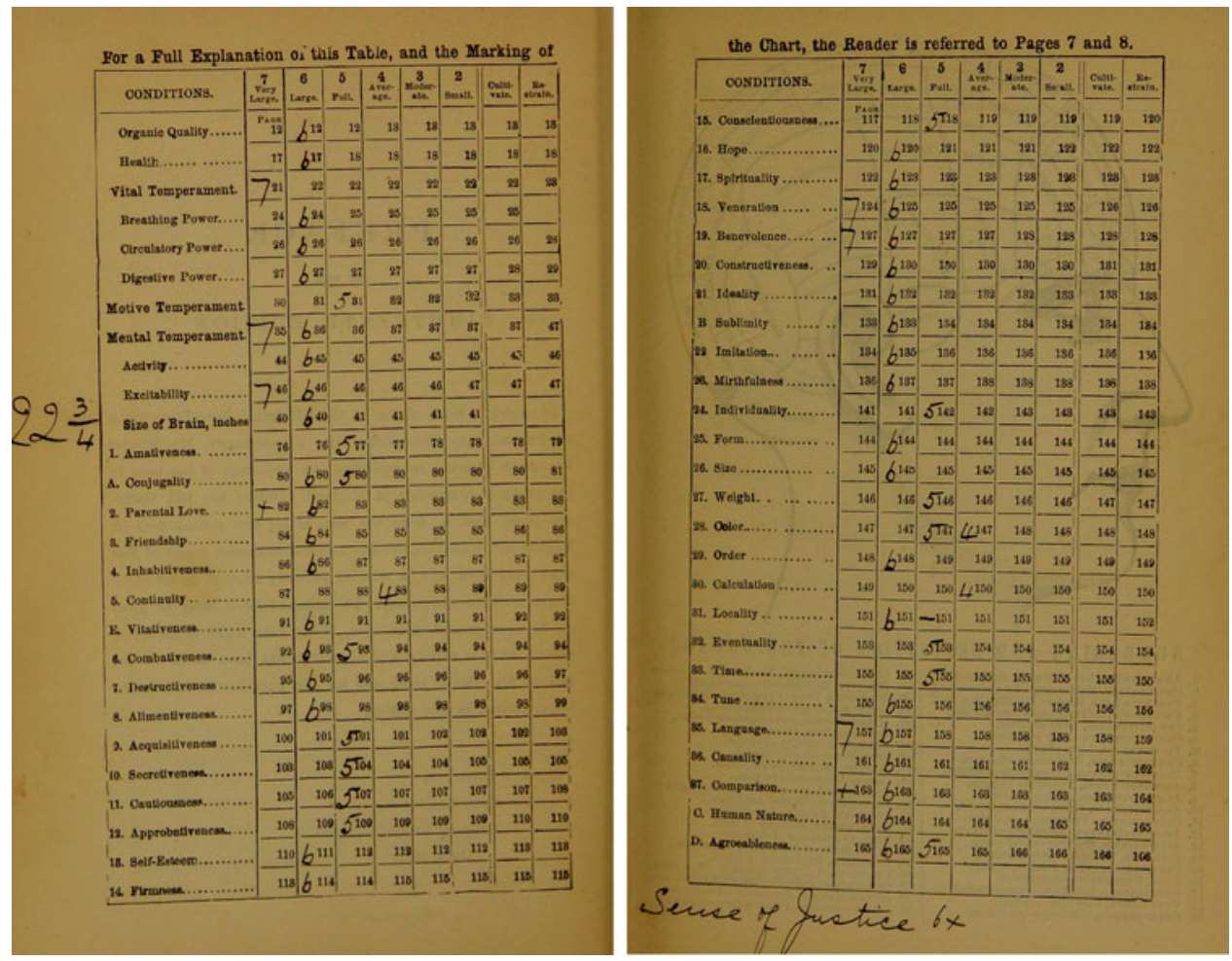

Figure 2. Fowler's New Illustrated Self-Instructor in Phrenology and Physiology: With over One Hundred Engravings, Together with the Chart and Character of [Mrs Peek] as Marked by [L.N. Fowler, London, 17 July 1891] (London: L.N. Fowler, 1891), London, Wellcome Library, K37479.

equal, is a measure of power'. ${ }^{42}$ It could be measured with tape, and sometimes other measurements such as the width of the head from ear to ear were added. ${ }^{43}$ Other phrenologists were less convinced by the importance of head size. Thomas Timson from Leicester found tape measurements sometimes misleading, and according to J.A. Houser, brain size said little about mental strength as the brain was like timber: it could be soft and inactive, or strong. ${ }^{44}$

42 Orson Fowler and Lorenzo Fowler, New Illustrated Self-Instructor in Phrenology and Physiology: With over One Hundred Engravings; Together with the Chart and Character of [blank line] as Marked by [blank line], New York: Fowler \& Wells, 1876, p. 38.

43 Joseph Millott Severn, Popular Phrenology, UCLA Library Special Collections, BF871.S498po 1918, p. 28.

44 Thomas Timson, The Self-Instructor and Phrenological Chart: Being a Delineation of Character, Talents, Health, Physical Development and Present Condition of Name ... Date ... As Given by Prof. T. Timson, Leicester, n.d., UCLA Library Special Collections BF871.T586s 1898, 17; and Prof. J.A. Houser's Chart of the Phrenological Developments of [C. C. Knauer [?], July [?] 9, 1882] as given by [Prof. 
The bumps on the head were not usually measured, although there were phrenologists who insisted that they were measurable: 'The difference in growth', according to Charles Olin, 'between a large and a small organ, in those of the propensities and some of the sentiments, amount to an inch and upward, and to a quarter of an inch in the organs of intellect' ${ }^{45}$ The size of bumps, however, was usually determined in relative and not absolute size, thus providing a great deal of freedom for the examiner. Although one of the booklets tells examiners to make sure that they do not to mark too high, every single individual in the collection of charts used for this paper scores above average. ${ }^{46}$ 'The measurement of the head', one phrenologist writes typically in the margin, 'is above average + you are capable of taking a more important position in life', ${ }^{47}$

Both the numbers and the layout of the tables guaranteed that an individual's score, compared to the supposed average, quickly caught the eye. The charts used a variety of scales but clients usually scored high numbers. On Messrs. Kidd \& Murphy's Phrenological Chart, for example, client Benjamin Pearson consistently scores 16 or 17 on a scale of 1 to 20 (Figure 1), while phrenologist Mrs Clitherow's client, Miss Jarvis, scored an average of 16.5 on a scale of 10 to 20 (Figure 3). On the most common scale of 1 to 7 , clients typically scored 5 or 6 , with 4 identified as the average. Most tables had one column for average scores, and most clients' scores were all in the columns to the left of the average so they would know with a quick glance that their head was of good quality. ${ }^{48}$

This positive message explains the appeal of phrenology, but also shows that here the techniques of science were more a matter of rhetoric than of objective content. That the charts could still be persuasive can partly be explained, as Michael Sokal describes, because of the Barnum effect: the tendency of people to rate descriptions of their personality that supposedly are tailored specifically for them as accurate, while in fact they are so vague and general that they would apply to almost all people. For example, they emphasize an above-average intelligence but hint at anxiety and self-doubt. ${ }^{49}$

All the charts - some a little more, some a little less - also had the characteristics of certificates: authoritative artefacts that suggest the professionalism of their makers and

Moore] J.A. Houser, M.D., Arcadia, IN: J.A. Houser, 1878, UCLA Library Special Collections, BF871.H842p 1878, p. 4.

45 Olin, op. cit. (19), p. 56. See also BF851 R287 1903: Reading Character from the Head; Or, the Success, Power and Ability of Man as Read from His Head: A Thorough and Practical Course of Instructions, New York: American Society of Scientific Research, c.1903, p. 31.

46 Human Nature Explained: A New Illustrated Treatise on Human Science for the People by N.N. Riddell; as Assisted by Louise E. Francis, New York, Riddell \& Francis, 1895, UCLA Library Special Collections 307. BF871.R543h 1895, p. 307.

47 The Phrenological \& Physiological Register: With Chart Describing the Phrenological Developments of $M r$ [R.A. Price] as Given by [Professor Bourne], date [July 1929], n.p., UCLA Library Special Collections BF871.P576 1929.

48 Messrs Kidd \& Murphy’s Phrenological Chart, n.p., c.1850, UCLA Library Special Collections, no inv. no.

49 Michael Sokal, 'Practical phrenology as psychological counseling in the 19th-century United States', in Christopher D. Green, Marlene Shore and Thomas Teo (eds.), The Transformation of Psychology: Influences of 19th-Century Philosophy, Technology, and Natural Science, Washington, DC: American Psychological Association, 2001, pp. 21-44. 


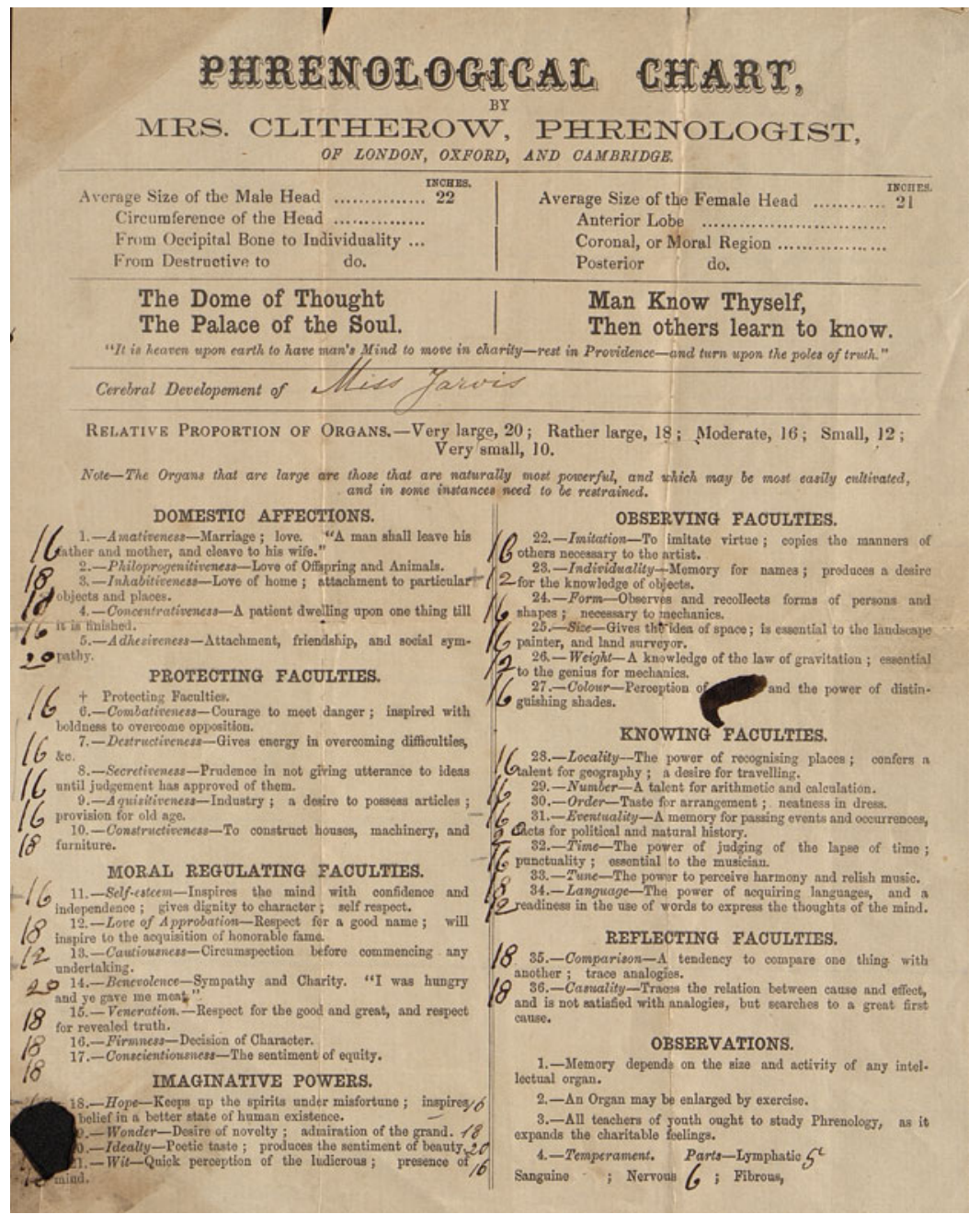

Figure 3. Mrs Clitherow, Phrenological Chart, no date, History \& Special Collections for Medicine and the Sciences, UCLA Library Special Collections, Ms. Coll. no. 504.097.

the validity of their content. This usage was well known in the history of universities (diplomas) and also outside it (stock certificates). The credibility of these papers was based on their layout, and on the institutions behind them. ${ }^{50}$ Like other certificates, each phrenological chart mentioned the name of the phrenologist, sometimes giving several professional titles; almost all of them mentioned the name of the client. Orson and Lorenzo Fowler's Illustrated Self-Instructor and later New Illustrated Self-

50 Lisa Gitelman, Paper Knowledge: Towards a Media History of Documents, Durham, NC and London: Duke University Press, 2014, p. 5. 
Instructor (Figure 2) are examples of the simplest kind, booklets which have a table on two pages in the middle, with the name of the client and of the examiner written on the page. ${ }^{51}$ The London-based Mr and Mrs Stackpool O'Dell had their charts stamped by a seal of authenticity, saying 'The O'Dells' London Phrenological Institution. The marking of these tables is only reliable when bearing this stamp'. ${ }^{52}$

As a general rule, the one-page charts included less text than the booklets but relied more on decorative frames. Take Messrs. Kidd \& Murphy's Phrenological Chart, from the UK, around 1850, a broadsheet-sized example that includes an elaborate ribbon of decoration with images of sailing ships; the slogan 'Man, Know Thyself'; a short text on the principles of phrenology; a list with the faculties, their use and abuse; and the score of the client. The client's temperament-phrenology included humoral theory too - is 'Nervous Sanguine', his size of brain 'Rather Large' (see Figure 1). ${ }^{53}$ Dr. R. Dilks' Phrenological Chart (Figure 4) had a decorative ribbon too, and the name of the client and the phrenologist in the upper centre, but also managed to include text, the list with faculties, and space for written comments. ${ }^{54}$ In an age of increasingly standardized forms, printers knew better and better how to design certificates, as can be seen, for example, in the collection of ribbons, logos and typefaces in Harpel's Typograph, or Book of Specimens. ${ }^{55}$

As these examples show, both the scientific and the certificate layout gave the charts a powerful rhetorical significance, with their numbers and tables as symbols of meticulousness and objectivity, and their stamps, decoration and scientific language adding to their authority. These made the charts attractive to the larger public that was beginning to appreciate the visual and numerical culture of science. They can be seen, therefore, as invitations to self-reflection. Like future psychological tests, the charts introduced individual consumers to new conceptions of personality and its location in the brain; moreover, they quantified and visualized individual difference. ${ }^{56}$

With respect to the appeal of the results of measurements to the public, the charts are comparable to the papers with measurements received by consumers who visited Francis

51 Orson Fowler and Lorenzo Fowler, The Illustrated Self-Instructor in Phrenology and Physiology: with One Hundred Engravings and a Chart of the Character ... as Given by ..., New York: Fowlers and Wells, several editions between c.1840 and 1859; and Fowler and Fowler, New Illustrated Self-Instructor in Phrenology and Physiology: With over One Hundred Engravings; Together with the Chart and Character of ... as Marked by ..., New York: Fowler \& Wells, several editions after c.1859.

52 See, for example, Stackpool E. O'Dell and Catherine Stackpool E. O'Dell, A Phrenological Chart of Character: (with Supplementary Tables), London: The London Phrenological Institution, n.d., UCLA Library Special Collections WB 365 O23p 1908, WB 365 O23p 1913 and WB 365 O23p 1918.

53 Messrs Kidd \& Murphy's Phrenological Chart (c.1850), UCLA Library Special Collections, no inv. no.

54 Phrenological Chart: In Which Is Set Forth the Character and Talents of [Mr HC Smith] Given by Dr. R. Dilks, no publisher, completed 24 September 1853, UCLA Library Special Collections, Ms Coll. no 504.405 .

55 Oscar H. Harpel, Harpel's Typograph, or Book of Specimens, Containing Useful Information and a Collection of Examples of Letterpress Job Printing, arranged for the Assistance of Master Printers, Amateurs, Apprentices, and Others, Cincinnati, OH: Harpel, 1870. For an analysis of Harpel's book see Gitelman, op. cit. (50), pp. 38-52.

56 For psychological testing see Rose, Inventing Ourselves, op. cit. (8), pp. 89-90. 




Figure 4. Phrenological Chart: In Which Is Set Forth the Character and Talents of [Mr HC Smith] given by Dr. R. Dilks, completed 24 September 1853, History \& Special Collections for Medicine and the Sciences, UCLA Library Special Collections, Ms. Coll. no. 504.405.

Galton's Anthropometric Laboratory at the International Health Exhibition in London in 1884. Visitors to Galton's laboratory were assisted in taking seventeen different measurements on the body, and took the records home while Galton also kept a copy. Galton believed that continuous self-assessment would make better and healthier people. He 
had visited a phrenologist himself in his twenties but by 1884 he no longer believed that phrenologists could read individual characteristics from bumps on the head. ${ }^{57}$ According to Frans Lundgren, the enthusiasm of the public for their measurements shows how "the observational ideal of "mechanical objectivity" and associated modes of representation ... became an integrated part of a political vision of self-observation and self-reformation'. ${ }^{58}$ Like Galton's measurements of the public at the Health Exhibition, but starting half a century earlier, phrenology charts brought science to the public, applied to themselves and made to look authoritative.

\section{Engaging with science}

While at the International Health Exhibition there was a high degree of participatory activity, phrenological charts demanded even more engagement of clients. ${ }^{59}$ Clients were not seen as a passive audience but were expected to learn scientific practices and to study themselves at the same time. The Self-Instructor, for example, a phrenological manual and self-help kit including a personalized chart, emphasized how people could learn how to do phrenology and to analyse themselves and those around them. 'By encouraging its audience to "know thyself", historian Carla Bittel notes, "phrenology blurred the lines of expertise and gave an active, analytical role to users' ${ }^{60}$

Through the charts (and the text on the charts), consumers of phrenology were encouraged to learn its skills and to understand its basic scientific techniques, such as measurement, observation and quantification; to internalize it and to make it applicable to their own bodies and sense of self. Under the heading 'Applied phrenology in selfculture', phrenologist Melancthon Tope, for example, wrote, 'It is not enough to simply teach the science of Phrenology as such - the true science in its rudiments - but it must be taught so the learner will desire and know how to make its practical applications'. ${ }^{61}$ Likewise, phrenologist Frederick Bridges wrote in his booklet that it was meant 'to render easy and practical not only the principles of Phrenology as a science, but its practical application as an art'. ${ }^{62}$ The New Illustrated Self-Instructor said that the text was so full of important discoveries that it required 'to be STUDIED rather than merely read', thereby encouraging an active attitude. ${ }^{63}$

57 Daniel J. Kevles, In the Name of Eugenics: Genetics and the Uses of Human Heredity, Los Angeles and Berkeley: University of California Press, 1985, p. 6.

58 Frans Lundgren, 'The politics of participation: Francis Galton's Anthropometric Laboratory and the making of civic selves', BJHS (2013) 46(3), pp. 445-466, 445.

59 For performance and the history of science see Iwan R. Morus, 'Placing performance', Isis (2010) 101, pp. $775-778$.

60 Bittel, op. cit. (14), p. 105.

61 Melancthon Tope, Tope's Newly Revised Practical Phrenological Chart, Bowerstone, OH: M. Tope, 1933, p. 81, UCLA Library Special Collections BF871.T673t 1933, original emphasis.

62 Frederick Bridges, Phrenology made Practical and Popularly Explained, London: Sampson Low, 1857, p. 6.

63 Orson Fowler and Lorenzo Fowler, New Illustrated Self-Instructor in Phrenology and Physiology: With over One Hundred Engravings; Together with the Chart and Character of ... as Marked by ..., New York: S.R. Wells, c.1859, p. vii. 
For readers to understand where the organs were located, all charts except the simplest included drawings or engravings of heads, but because heads differed in size or shape, people had to take into account that the place of organs varied slightly on every head. ${ }^{64}$ 'So the best rule I can give', wrote phrenologist Stephen Tracht, 'is, take [the organs] in rotation and judge the distance according to the size of the head'. This was something everyone could learn, according to Tracht: 'In the study of Phrenology the Organs can very easily be located after a little practice'. ${ }^{65}$ Orson and Lorenzo Fowler let the fingers do the work: 'To find these two organs [destructiveness and secretiveness], and their relative size, place the third fingers of each hand upon the head just at the top of the ears; let the lower side of the third finger be even with the upper part of the ear; that finger then rests upon Destructiveness'. ${ }^{66}$ Only Enos Stevens took location more seriously and defined the position of the organs with their distance from the planes of the tentorium (a horizontal line from ear to ear) and the falx (a line from nose to the back or the neck), just as the location of a place on earth is defined by its longitude and latitude. He included a table with the distances to these two lines of each organ. ${ }^{67}$

Phrenologists portrayed phrenology as a simple, positive science that they were happy to explain to others. However, while it was easy for individual users who wanted to practise phrenology to take a tape measure to gauge head circumference, the assessment of the bumps (in relative size) was a lot more difficult, as the examiner was supposed to evaluate bumps based on experience and comparison. Most booklets were rather vague about how one was to interpret the bumps, but there were phrenologists who gave some guidance, such as James Coates: 'So as to be able to approximate to the exact size without the use of tape, accustom your eye to take measurements. If you were an artist you would not take out "a two-foot rule," or tape line, to take the dimensions of a lady's nose before you paint her portrait'. ${ }^{68}$ This also meant, 'It needs to be read and applied with common sense, not taken too literally, and not looked upon as a sort of infallible mathematical index to character'. ${ }^{69}$

Another important scientific skill that the charts taught was the ability to read the numbers and tables. The different booklets explain to the reader in detail how to do that:

The strength of the several vital functions and elements of the mind is estimated in the scale of seven, the several degrees are indicated by numerals $1,2,3,4,5,6,7 \ldots$ The examiner will

64 For engravings of the head see (among many others), Philemon Sohier, Phrenological Developments, Together with the Character and Talents of ... by the Phrenologist: Sohier, completed 9 February 1860, Wellcome Library, London, EPH+37.

65 Tracht, op. cit. (31), p. 13.

66 Orson Fowler and Lorenzo Fowler, The Illustrated Self-Instructor in Phrenology and Physiology: With One Hundred Engravings and a Chart of the Character of [S.S. Kimball] as Given by [N. Sizer, 21 April 1855], UCLA Library Special Collections, BF870.F787i 1855, 128. Charles Olin also described how the finger should follow lines on the head. Olin, op. cit. (19), p. 55.

67 Stevens, op. cit. (41).

68 James Coates, How to Read Heads; Or, Practical Lessons on the Application of Phrenology to the Reading of Character, London: Simpkin et al., 1891, 27.

69 A Phrenological Chart of Character: (with Supplementary Tables) by Stackpool E. O’Dell \& Mrs. Stackpool E. O’Dell, London: The London Phrenological Institution, 1879. Completed for Mr Davis, 18 February, UCLA Library Special Collections 1935WB 365 O23p 1931. 
indicate the degree of strength of each function or element by placing the figure representing it in the first column to the right. When an organ is estimated to be half way between two degrees, it will be indicated by two figures, as 3 to 4 , or 5 to 6 , etc., which is equivalent to $3 \frac{1 / 2}{2}$ or $5 \frac{1}{2} \ldots$ Where an element is a fraction above or below a degree the plus $(\mathrm{x})$ or minus $(-)$ mark will be used. $^{70}$

As Patricia Cline Cohen has shown, there was a growing familiarity with numbers in the US by the mid-nineteenth century. Reading the explanations in the phrenological charts built on this knowledge of numbers and at the same time made the public more scientifically literate. ${ }^{71}$

Charts were usually filled in by the phrenologist but the booklets were written with the suggestion that the reader should not only understand the ideas behind phrenology but also be able to replicate them at home. 'This chart', wrote Melancthon Tope, 'has been made so simple, explanatory and true that any one who understands mental geography can mark it correctly for himself and any one else'. ${ }^{72}$ Professional phrenologists themselves had usually started the same way, testing phrenology on their own heads or those of their friends. According to Van Wyhe, 'Virtually all the phrenologists who left sufficient record for us to examine show that they first tried phrenology to see if it worked'. ${ }^{73}$

That active engagement did take place in the home we can see from examples such as the book Evenings at Home: How to Spend Them (1891), which includes - besides 'acting charades' and 'proverbs and old sayings' - a chapter on phrenology. ${ }^{74}$ Carla Bittel describes the case of Louisa Maria Macomber, who used a copy of J. Stanley Grimes's 1853 Compend of the Phreno-philosophy of Human Nature to analyse herself. Macomber found herself positive in Comparison, Causality and Cautiousness. ${ }^{75}$ Several other charts show how readers engaged with the text or with the results of the examination. One anonymous owner of a booklet looked up difficult or Latin words and wrote their meaning in the margins. The translation of 'non compos mentis' for example, was written in pencil as 'not of sound mind'. ${ }^{76}$ Henry S. Prentiss put question marks in his version of the phrenological manual, especially in those paragraphs that defined him as a serious person and good at mathematics. ${ }^{77}$ It shows that the clientele did not take phrenological advice for granted.

70 Human Nature Explained: A New Illustrated Treatise on Human Science for the People by N.N. Riddell; as Assisted by Louise E. Francis, New York: Riddell \& Francis 1895, UCLA Library Special Collections BF871. R543h 1895, p. 2 of the descriptive chart at the back.

71 Patricia Cohen, A Calculating People: The Spread of Numeracy in Early America, Chicago: The University of Chicago Press, 1982.

72 Tope, op. cit. (61), p. 5.

73 Van Wyhe, op. cit. (11).

74 Nugent Robinson, Evenings at Home: How to Spend Them, New York: Collier, 1891, pp. 346-361.

75 Bittel, op. cit. (14), p. 118.

76 Orson Fowler and Lorenzo Fowler, New Illustrated Self-Instructor in Phrenology and Physiology: With over One Hundred Engravings; Together with the Chart and Character of [blank line] as Marked by [blank line], New York: Fowler \& Wells, n.d., UCLA Library Special Collections BF870.F787i 1859b, copy 1, for this example see p. 13.

77 John Cowan, Self-Help: In the Attainment of Perfection of Character and Success in Life, with a Phrenological \& Physiological Chart of the Character of [Henry S. Prentiss] as Given by [H.E. Swain, 6 March 1880, Princeton College], New York: Cowan \& Company, 1880, UCLA Library Special Collections BF871.C874s 1880 . 
A simple distinction between the all-knowing scientist and the research subject therefore does not apply to practical phrenology. Learning about phrenology did not stop when clients left the office of the phrenologist because with the charts they had acquired they were invited to acquire the knowledge and the skills to investigate themselves and others. It was in the interest of phrenologists that people would visit them and pay for their visit, but the rhetoric of self-knowledge that was part and parcel of phrenology meant that scientific practices, both the passive understanding of numbers and tables and the active use of the fingers and tape measure, did circulate among the wider public.

It was in such practices that new senses of selfhood were shaped. The charts' encouragement to study text, numbers and tables, and to make observations and examinations of heads, stimulated individuals to use these scientific skills to direct attention to themselves. In the process, and with this new scientific mindset, consumers of phrenology were able to internalize the principles of phrenology and learned how to see themselves in relation to others. Thus the charts provided not only the conceptual basis and the language but also the practical tools for self-knowledge.

\section{Conclusion}

The most recent completed chart in the UCLA collection is from 1939. It was filled in for Miss Monica Horn, and the examination was made by the London phrenologist Mrs Catherine Stackpool O'Dell. It differed little from earlier charts, although it was quite elaborate and included health, marriage and dietary advice. Miss Horn was instructed to cultivate friendship and approbativeness. Mrs O'Dell had taken over her husband's phrenological business when he died in 1917 and continued it until a few years before her death in $1944 .{ }^{78}$ The phrenologist couple was remembered until after the war: in 1958 L. Dudley Stamp wrote in a letter to the editor of The Times saying that he himself had been examined by Mr Stackpool O'Dell at the age of six and that '50 years later I continue to be staggered by the accuracy of the diagnosis ... which guided my parents in my upbringing and to which I owe many of the unusual opportunities they afforded me'. ${ }^{79}$

The phrenological charts are an example of how paper tools were used by popularizers of science to reach a larger middle-class public. Clients of phrenologists were not only taught the 'facts' but also how these facts related to themselves as individuals, and, moreover, how they themselves would be able to arrive at those facts. By combining the layout of science and certificates, phrenologists made their charts as persuasive as possible, and with the quantification of their bumps, clients were given new data on themselves that they then could use for further self-reflection and self-development. This personal tailoring of the charts conveyed possible new understandings of the inner self, and people also learnt more about themselves by learning the scientific skills that phrenology propagated. By learning how to do science, individuals were encouraged to internalize the idea that they had knowable selves and that they could be the experts upon them.

78 'Obituary', The Times, 19 February 1944, p. 6.

79 L. Dudley Stamp, 'Phrenology', The Times, 6 March 1958, p. 11. 